\title{
Tiotropium Bromide Attenuates Mucus Hypersecretion in Patients with Stable Chronic Obstructive Pulmonary Disease
}

\author{
Suyun Yu, ${ }^{1}$ Caili Zhang, ${ }^{2}$ Zhijun Yan, ${ }^{1}$ Qingqing Fang $\mathbb{D}^{3}$ and Xiwen Gao $\mathbb{D}^{1}$ \\ ${ }^{1}$ Department of Respiratory Medicine, Minhang Hospital Affiliated to Fudan University, Minhang District Central Hospital, \\ Shanghai 201199, China \\ ${ }^{2}$ Minhang Qibao Community Health Service Center, Shanghai 201108, China \\ ${ }^{3}$ Department of Gastroenterology, Minhang Hospital Affiliated to Fudan University, Minhang District Central Hospital, \\ Shanghai 201199, China
}

Correspondence should be addressed to Qingqing Fang; xxhafqq@163.com and Xiwen Gao; xiwengao@sina.com

Received 4 August 2021; Accepted 14 September 2021; Published 5 October 2021

Academic Editor: Jianxin Shi

Copyright (c) 2021 Suyun Yu et al. This is an open access article distributed under the Creative Commons Attribution License, which permits unrestricted use, distribution, and reproduction in any medium, provided the original work is properly cited.

\begin{abstract}
Background. Patients with stable chronic obstructive pulmonary disease (COPD) have been observed to benefit from tiotropium bromide. However, there are few studies of tiotropium bromide on sputum and sputum viscosity. To evaluate the effect of tiotropium bromide on mucus hypersecretion, a randomized, double-blind controlled trial was performed. Methods. 120 cases of patients with pulmonary function grade II were divided into two groups, which include the treatment group given tiotropium bromide powder inhalation $(18 \mu \mathrm{g}$, inhalation, QD) and the control group given formoterol fumarate powder inhalation ( $12 \mu \mathrm{g}$, inhalation, BID) plus ambroxol hydrochloride tablets (60 mg, oral, TID). After 3 months of treatment, the pulmonary function and $\alpha_{1}$-acid glycoprotein $\left(\alpha_{1}\right.$-AGP) in sputum were detected, and the changes of glycoprotein and $\mathrm{Ca}^{2+}$ content were evaluated by Miller classification. Results. Three patients $(2$ cases in the treatment group and 1 case in the control group) were dropped due to loss of follow-up, and 117 cases of patients were enrolled in this study. After 3 months of treatment, the sputum character score, $\alpha 1$-acid glycoprotein, $\mathrm{Ca}^{2+}$ content, and lung function of the two groups were significantly improved; group comparison analyses revealed that there was no significant difference in the content of $\alpha_{1}$-AGP, $\mathrm{Ca}^{2+}$ in sputum, and lung function between the two groups $(P>0.05)$, but the improvement of sputum properties was significant $(P<0.05)$, and the treatment group was better than the control group $(t=-2.77 ; P=0.007)$. Conclusions. Inhaled tiotropium bromide can effectively inhibit the mucus hypersecretion in stable COPD patients, improve the sputum properties and lung function of patients, and improve the quality of life of patients.
\end{abstract}

\section{Introduction}

Practically, chronic obstructive pulmonary disease (COPD) is characterized by persistent respiratory symptoms and airflow restriction [1]. In China, the incidence of COPD is $8.6 \%$, and the number of sufferers has surpassed 100 million, putting a significant economic and social strain on the country [2]. It is estimated that more than 5.9 million people die of COPD and its related diseases every year by 2060 [3] due to the limited treatment options [4] and alter the long-term decrease in lung function conclusively [5]. The majority of COPD medications on the market now are bronchodilators $[6,7]$ that offer clinical relief by removing reversible airway restriction, which is a common but not universal characteristic of COPD [5]. Inhaled long-acting bronchodilators (ILBs) in combination with inhaled corticosteroids (ICS) are now recommended for the maintenance treatment of moderateto-severe COPD [5], such as formoterol fumarate powder inhalation plus ambroxol hydrochloride tablets. Patients with COPD, on the other hand, are frequently unresponsive to corticosteroids, and patients using this class of antiinflammatory medicines may be at an increased risk of pneumonia [8]. The orally active PDE4 inhibitor roflumilast was recently launched as an anti-inflammatory medication for the treatment of COPD; however, it is only approved for use in severe patients and is dose-limited due to side effects, 
TABLE 1: The standard of clinical macroscopic observation of sputum characteristics.

\begin{tabular}{|c|c|c|c|c|}
\hline \multirow{2}{*}{$\begin{array}{l}\text { Symptoms/ } \\
\text { signs }\end{array}$} & \multicolumn{4}{|c|}{ Grading standard } \\
\hline & 0 points (-) & 1 points $(+)$ & 2 points $(++)$ & 3 points $(+++)$ \\
\hline $\begin{array}{l}\text { Characteristics } \\
\text { of sputum }\end{array}$ & $\begin{array}{l}\text { Pure and transparent, } \\
\text { nonmucinous sputum }\end{array}$ & $\begin{array}{l}\text { A little purulent } \\
\text { transparent sputum }\end{array}$ & $\begin{array}{l}\text { Purulent mucus } \\
\text { (purulent }<2 / 3 \text { ) }\end{array}$ & Purulent mucus (purulent $\geq 2 / 3$ ) \\
\hline $\begin{array}{l}\text { Difficulty of } \\
\text { expectoration }\end{array}$ & No phlegm & Sputum is easy to cough up & $\begin{array}{l}\text { Sputum is difficult to cough } \\
\text { up }\end{array}$ & On difficult cough \\
\hline $\begin{array}{l}\text { Sputum } \\
\text { volume }\end{array}$ & $\begin{array}{l}\text { The amount of } \\
\text { expectoration was less } \\
\text { than } 10 \mathrm{ml}\end{array}$ & $\begin{array}{l}\text { The expectoration volume } \\
\text { is } 10 \sim 50 \mathrm{ml} \text { day and night }\end{array}$ & $\begin{array}{l}\text { The expectoration volume } \\
\text { is } 50 \sim 100 \mathrm{ml} \text { day and night }\end{array}$ & $\begin{array}{l}\text { The amount of expectoration was } \\
\text { more than } 100 \mathrm{ml} \text { day and night }\end{array}$ \\
\hline Cough & No cough & $\begin{array}{l}\text { Mild cough, does not affect } \\
\text { normal life and work }\end{array}$ & $\begin{array}{l}\text { Between mild cough and } \\
\text { severe cough }\end{array}$ & $\begin{array}{l}\text { Severe cough, frequent cough day } \\
\text { and night, affect work and sleep }\end{array}$ \\
\hline
\end{tabular}

TABLE 2: Comparison of baseline data between the two groups.

\begin{tabular}{lcccc}
\hline Group & Cases & Sex ratio $(\mathrm{M} / \mathrm{F})$ & Min & \multicolumn{2}{c}{ Age (years) } \\
Max & 82 & $67.13 \pm 6.11$ \\
\hline Treatment & 58 & $35 / 23$ & 43 & 80 \\
Control & 59 & $39 / 20$ & 45 & $67.98 \pm 5.82$ \\
Test statistics & & $X^{2}=0.206$ & & $t=-0.765$ \\
$P$ value & & 0.65 & 0.446 \\
\hline
\end{tabular}

TABLE 3: Comparison of sputum indexes between the two groups before and after treatment.

\begin{tabular}{lcccccc}
\hline \multirow{2}{*}{ Group } & \multirow{2}{*}{ Cases } & \multicolumn{2}{c}{ Sputum score } & \multicolumn{2}{c}{$\alpha 1$-Acid glycoprotein } & \multicolumn{2}{c}{ Sputum Ca ${ }^{2+}$} \\
& & Before & After & Before & After & Before \\
\hline Treatment & 58 & $7.12 \pm 2.5$ & $3.98 \pm 1.39$ & $901.89 \pm 176.53$ & $517.24 \pm 103.25$ & $4.65 \pm 1.52$ \\
Control & 59 & $6.89 \pm 2.37$ & $4.71 \pm 1.45$ & $871.18 \pm 175.97$ & $536.03 \pm 116.26$ & $4.39 \pm 1.46$ \\
$t$ value & & 0.594 & -2.77 & 0.715 & -0.65 & $2.99 \pm 0.55$ \\
$P$ value & & 0.554 & $\mathbf{0 . 0 0 7}$ & 0.476 & 0.518 & -0.462 \\
\hline
\end{tabular}

TABLE 4: Comparison of pulmonary function between two groups of COPD.

\begin{tabular}{|c|c|c|c|c|c|}
\hline \multirow{2}{*}{ Group } & & \multicolumn{2}{|c|}{ FEV1/FVC } & \multicolumn{2}{|c|}{ FEV1/predicted value } \\
\hline & & Before & After & Before & After \\
\hline Treatment & 58 & $52.39 \pm 6.65$ & $59.29 \pm 7.24$ & $59.51 \pm 5.85$ & $66.89 \pm 5.70$ \\
\hline Control & 59 & $51.44 \pm 5.64$ & $58.83 \pm 5.07$ & $58.67 \pm 5.63$ & $65.98 \pm 6.24$ \\
\hline$t$ value & & 0.838 & 0.399 & 0.79 & 0.825 \\
\hline$P$ value & & 0.399 & 0.691 & 0.431 & 0.411 \\
\hline
\end{tabular}

notably in the gastrointestinal tract [9]. As a result, new therapeutic methods for COPD therapy, as well as a variety of innovative bronchodilators, are required [10], and antiinflammatory drugs [11] and bifunctional agents [12] are under development for the treatment of this disease.

One of the main features of COPD is airway mucus hypersecretion, which presents clinically as a persistent cough and expectoration. Excess mucus clogs the airways, causing airflow restriction and increasing the risk of bacterial infection. This leads to worsening airflow restriction, decreased airway mucociliary transport, respiratory infec- tion, and acute COPD exacerbations (AECOPD) [13, 14]. Formoterol fumarate is a long-acting $\beta 2$-adrenergic agonist used to prevent COPD-induced bronchospasm [15]. Published studies have shown that formoterol fumarate has a rapid bronchiectasis effect [16], which may enhance compliance, and continue bronchiectasis within 12 hours, with a cumulative effect when inhaled twice a day. Ambroxol hydrochloride tablets are mainly suitable for patients with thick sputum that is not easy to cough up [17]. Studies have shown that after treatment with ambroxol hydrochloride tablets, the number of inflammatory cells and plasma 
TNF- $\alpha$, IL-8, and IL-6 levels in COPD rats were significantly reduced after treatment, and lung tissue inflammation was reduced [18].

Tiotropium is a long-acting second-generation muscarinic receptor antagonist that works by blocking acetylcholine binding to the M1, M2, and M3 muscarinic acetylcholine receptors (mAChRs) in the lungs. The quaternary ammonium compound binds reversibly to M1 $\mathrm{mAChRs}$ of the nerve ganglia of the lung, M2 mAChR postganglionic nerve fibers of the lung, and M3 mAChRs of the smooth muscles and mucous glands of the lung when the patient inhales the drug as an inhalation spray or inhalation powder. When tiotropium binds to the M1 and M3 mAChRs, it prevents the influx of intracellular calcium from generating a cellular response in the respiratory airways by blocking $\mathrm{Gq}$ alpha-protein activation of the phospholipase C pathway [19]. Bronchodilation, decreased mucous gland secretions, decreased ciliary beat frequency, suppression of fibroblast proliferation, and a poorly known antiinflammatory action in the lungs are all effects of tiotropium's anticholinergic effect on the respiratory airway [20-23]. However, tiotropium was reported to improve the lung function of COPD patients. There are few studies of tiotropium bromide on sputum and sputum viscosity. In this study, tiotropium bromide inhalation was used to observe the stable COPD patients with phlegm and mucus, and formoterol fumarate powder inhalation combined with ambroxol hydrochloride tablets were used as control. Our findings showed that inhaled tiotropium bromide could effectively inhibit the mucus hypersecretion in stable COPD patients and improve the sputum properties and lung function of patients, so as to improve the quality of life of patients.

\section{Materials and Methods}

2.1. Main Equipment and Drugs. The main equipment and drugs used were as follows: automatic biochemical analyzer (Olympus AU2700), centrifuge (Eppendorf, Centrifuge 5804R), spiral oscillator, electronic balance (Mettler-Toledo Instruments Co., Ltd., Switzerland), phosphate buffer (PBS), dithiothreitol (DTT), $\alpha_{1}$-acid glycoprotein ( $\alpha_{1}$-AGP) reagent, and supporting calibration solution (No. 2672, Landau Company, UK). The lung function instrument used was the Quark PFT4 Ergo.

2.2. Study Population. The study was carried out with patients recruited at the Department of Respiratory Medicine, Minhang Hospital Affiliated to Fudan University, where they attended periodic control visits for COPD. Recruitment was carried out from January 2019 to July 2019.

The inclusion criteria were as follows: outpatients aged between 40 and 82 years old, FEV1/FVC was less than $70 \%$ and FEV1 was less than $80 \%$ and greater than or equal to $50 \%$ after clinical diagnosis of COPD and bronchodilator use, clinically stable period reached 6 weeks or more after the last aggravation, patients with excessive phlegm and sticky phlegm, and COPD was divided into GOLD B [5].
The exclusion criteria were as follows: patients who were suffering from other pulmonary diseases, such as bronchial asthma, pneumonia, bronchiectasis, and lung cancer; patients who were suffering from severe heart, liver, and kidney dysfunction; patients who were suffering from severe neuropsychosis; patients who were suffering from severe prostatic hyperplasia combined with urinary retention, angle closure glaucoma, etc.; pregnant or lactating women; patients who were using oral or inhalational preparations that contain anticholinergic drugs; and patients who were unable or unwilling to continue.

The study design was authorized by the Ethics Committee of Minhang District Central Hospital with respect to the guidelines of the Declaration of Helsinki. Each participant gave written informed consent to participate in the study.

2.3. Study Design. Pulmonologists and geriatricians recruited and selected patients according to the abovementioned inclusion criteria. Finally, a total of 120 patients with stable COPD were included, all of whom matched the diagnostic criteria of the guideline for the diagnosis and management of the chronic obstructive pulmonary disease.

These patients were randomly divided into two groups, the treatment group and the control group, with 60 cases, respectively. The treatment group was given tiotropium bromide powder inhalation (18 $\mathrm{g}$, inhalation, QD) (Zhengda Tianqing Pharmaceutical Group Co.). The control group was given formoterol fumarate powder inhalation $(12 \mu \mathrm{g}$, inhalation, BID) (Zhengda Tianqing Pharmaceutical Group Co.) combined with ambroxol hydrochloride tablets (60 mg, oral, TID) (Boehringer Ingelheim Shanghai Pharmaceutical Co.). The sputum specimens were collected and lung function was examined before and after treatment.

2.4. Collection and Treatment of Sputum Samples. Sputum samples were collected according to routine requirements. All subjects were treated with a disposable sputum collector before treatment and 3 months after treatment, and at least $2-3 \mathrm{ml}$ of deep sputum was collected. Sputum samples were collected by the same person from 8:00 AM to 9:00 AM.

Two to $3 \mathrm{ml}$ sputum was added with $0.1 \%$ dithiothreitol (DTT), 4 times the volume of the sputum; then, the mixture was shaken for $15 \mathrm{~min}$ with a spiral oscillator, and then the same volume of PBS was added. Finally, the mixture was shaken for $5 \mathrm{~min}$ and centrifuged for $10 \mathrm{~min}$ at $3000 \mathrm{rpm}$. The supernatant was placed at $-70^{\circ} \mathrm{C}$ for determination.

\subsection{Assessment Methodology}

2.5.1. Subjective Indicators. For the clinical macroscopic observation of sputum characteristics, the standard is shown in Table 1, referring to Miller's classification.

2.5.2. Objective Indicators. For objective indicators, sputum $\alpha_{1}$-AGP and $\mathrm{Ca}^{2+}$ (its content increased with the increase of sputum viscosity) and a lung function test (operated by the same person) were used. The $\alpha_{1}$-AGP kit of this test was purchased from Randox (UK). It was used to detect the content of $\alpha_{1}$-AGP in the samples by immunoturbidimetry on an automatic biochemical analyzer. For the lung 
function test, the lung function of the patients was checked on the first day and after 90 days, which include checking FEV1/FVC and FEV1\% of the predicted value (FEV1\%). The test should be repeated twice, the high value should be taken, and the difference between the two tests should be less than $5 \%$.

2.6. Statistical Analyses. The data were analyzed using SPSS 21.0 statistical software (SPSS Inc.); mean \pm standard deviation (SD) was used to express the age, sputum, and pulmonary function score before and after treatment; and $t$-test was used to compare within and between groups. Test level is $\alpha=0.05$.

\section{Results}

3.1. Tiotropium Bromide and Formoterol Fumarate Combined with Ambroxol Hydrochloride Demographics. Pulmonologists and geriatricians recruited and selected patients according to the inclusion criteria. In our study, 120 patients with stable COPD were included who satisfied the diagnostic criteria of the guideline for the diagnosis and treatment of chronic obstructive pulmonary disease. Due to the loss of follow-up, there were 2 cases in the treatment group and 1 case in the control group who were dropped. Finally, a total of 117 patients were included in the study. No adverse events occurred in all cases. There were 58 patients in the treatment group, including 35 males and 23 females, aged from 43 to 82 years, with an average of $67.13 \pm 6.11$ years. There were 59 cases in the control group, including 39 males and 20 females, aged from 45 to 80 years, with an average of 67.98 \pm 5.82 years. The baseline data of the two groups were comparable, and there were no among-group differences in gender and age index (Table 2).

3.2. Tiotropium Bromide Improves the Sputum Properties of Patients with COPD. To explore the effect of tiotropium bromide on sputum indexes, the sputum score, $\alpha 1$-acid glycoprotein, and sputum $\mathrm{Ca}^{2+}$ of the two groups were detected. As shown in Table 3, there were no statistically significant differences between the two groups in the sputum score $(P=0.554), \quad \alpha_{1}$-AGP $\quad(P=0.476), \quad$ and sputum $\mathrm{Ca}^{2+}$ $(P=0.213)$. After treatment, no matter in the treatment group or control group, all of the sputum indexes were improved obviously. Furthermore, we also compared the pharmacodynamic effects of tiotropium bromide and formoterol fumarate combined with ambroxol hydrochloride. The results showed that there were nonsignificant improvements in $\alpha_{1}$-AGP $(P=0.518)$ and sputum $\mathrm{Ca}^{2+}(P=0.644)$, but positive effect estimates for sputum score $(P=0.007)$. Our findings demonstrated that tiotropium bromide could improve the chronic sputum production in COPD and the phenotype of those with chronic sputum symptoms, suggesting the novel function of tiotropium bromide in improving sputum properties.

3.3. Tiotropium Bromide Improves the Lung Function of Patients with COPD. Next, we investigated whether the introduction of tiotropium bromide in stable-phase COPD patients could improve lung function, physical performance, and quality of life. Before treatment, all the COPD patients suffered from bronchiarctia, and there was no significant difference in FEV1/FVC and FEV1/predicted value between the two groups. After treatment, the FEV1/FVC and FEV1/predicted values in the two groups were significantly increased $(P<0.05)$. Moreover, we also compared the pharmacodynamic effects of tiotropium bromide and formoterol fumarate combined with ambroxol hydrochloride on lung function. After therapy, we discovered that there was no significant difference between the two groups (Table 4), indicating that tiotropium bromide worked just as well as formoterol fumarate combined with ambroxol hydrochloride in improving the lung function of patients with COPD.

\section{Discussion}

COPD is a common and frequently occurring disease of the respiratory system [24]. The incidence and mortality are increasing year by year. The pathogenesis is still unclear. Chronic cough, sputum, and obstruction of the airway lead to the continuous decline in lung function. The quality of life is declining. It has brought a great economic burden to society and families. The global initiative for the prevention and treatment of COPD (GOLD) 2020 [25] points out that inhalation therapy is the first choice for stable COPD, and inhaled bronchodilators play a particularly important role in controlling the symptoms of COPD.

The most important pathophysiological changes of COPD are airway obstruction and airflow limitation. Studies have shown that airway mucus hypersecretion can aggravate small airway obstruction and reduce ciliary clearance function [26], which is an independent risk factor for the condition and prognosis of COPD. How to effectively inhibit the high expression of mucin is an important part of COPD research. The innervation of airway secretory cells includes three neural pathways: sympathetic (adrenergic), parasympathetic (cholinergic), and nonadrenergic and noncholinergic (NANC) innervation. Cholinergic nerve innervates mucus movement and respiratory secretions. Release of acetylcholine cholinergic nerve activated submucosal gland cells and stimulated mucus secretion. This is because these two illnesses are characterized by mucus hypersecretion, and muscarinic agonists promote mucus production. Tiotropium bromide is a new type of anticholinergic drug, and formoterol fumarate inhibits cholinergic and NANC-induced contractions [27]. In this study, we found that after 3 months of treatment, the sputum trait scores, $\alpha 1$-acid glycoprotein, $\mathrm{Ca}^{2+}$ content, and lung function of COPD patients in the two groups were improved. Recent animal studies have shown that rhinovirus (HRV) increases the production of mucin in the differentiation medium of primary human bronchial epithelial cells (ALI-PBEC), while fluticasone and tiotropium bromide can reduce the production of mucin induced by HRV. Another basic study [28] showed that tiotropium bromide reduced NE-stimulated MUC5AC, but had no effect on IL-13-stimulated MUC5AC. These results may be due to the increased production of acetylcholine by IL-13. In asthma research [29], a high dose tiotropium bromide was used to treat acute and recurrent allergic asthma in 
mice. It was concluded that tiotropium bromide could effectively inhibit airway and parenchymal inflammation and mucus hypersecretion. Similarly, some researchers [30] used tiotropium bromide $(18 \mu \mathrm{g} / \mathrm{d})$ to treat patients with airway mucus hypersecretion of DPB who did not respond to macrolide drugs. Some of the results after using tiotropium bromide are as follows: the visual analogue scale (VAS) score was significantly improved; FEV1 was significantly improved after 3 months of tiotropium bromide treatment; and cough, sputum, and dyspnea symptoms of macrolideresistant DPB patients were improved. Experimental results show that the sputum properties of COPD patients treated with tiotropium bromide were significantly improved. The effect may be due to the inhibition of airway secretion by tiotropium bromide through its anticholinergic effect on submucosal glands.

The deficiency of this study is that the sample size is small, and the COPD patients in group A, group C, and group $\mathrm{D}$ have not been observed. The next step is to expand the clinical observation sample and observation cycle, and deepen the mechanism of the effect of tiotropium bromide, on sputum hypersecretion, so as to provide a theoretical basis for the treatment of COPD.

Previous studies on COPD have focused on the bronchiectasis of anticholinergic drugs [31]. However, there are few studies on its function in sputum. The results of this study showed that after 3 months of treatment with tiotropium bromide, the indexes of sputum viscosity by naked eye observation and objective reflection showed the improvement of sputum viscosity in COPD patients, and the improvement of lung function. Considering its role in improving the characteristics of sputum, it is involved in the improvement of lung function.

\section{Data Availability}

All data analyzed during this study are obtained from published articles or are available from the corresponding authors on reasonable request.

\section{Ethical Approval}

This study was approved by the Ethics Committee of Minhang District Central Hospital, and all patients' written informed consents were obtained.

\section{Conflicts of Interest}

The authors declare that they have no competing interests.

\section{Authors' Contributions}

SY, QF, and XG performed the study and drafted the article. SY, CZ, and ZY conducted data acquisition, data analysis, and interpretation. All authors discussed the results and agreed to be accountable for all aspects of the work. All authors read and approved the final manuscript.

\section{Acknowledgments}

This study was supported by the Beijing Medical and Health Public Welfare Fund Project (No. YWJKJJHKYJJHX16) and the Minhang District Natural Science Research Project, Shanghai (No. 2020MHZ097).

\section{References}

[1] A. R. Patel, A. R. Patel, S. Singh, S. Singh, and I. Khawaja, "Global Initiative for Chronic Obstructive Lung Disease: the changes made," Cureus, vol. 11, no. 6, article e4985, 2019.

[2] C. Wang, J. Xu, L. Yang et al., "Prevalence and risk factors of chronic obstructive pulmonary disease in China (the China Pulmonary Health $(\mathrm{CPH})$ study): a national cross-sectional study," Lancet, vol. 391, no. 10131, pp. 1706-1717, 2018.

[3] J. L. Lopez-Campos, J. J. Soler-Cataluna, and M. Miravitlles, "Global strategy for the diagnosis, management, and prevention of chronic obstructive lung disease 2019 report: future challenges," Arch Bronconeumol (Engl Ed), vol. 56, no. 2, pp. 65-67, 2020.

[4] M. Cazzola, P. Rogliani, J. Ora, and M. G. Matera, "Treatment options for moderate-to-very severe chronic obstructive pulmonary disease," Expert Opinion on Pharmacotherapy, vol. 17, no. 7, pp. 977-988, 2016.

[5] C. F. Vogelmeier, G. J. Criner, F. J. Martinez et al., "Global strategy for the diagnosis, management, and prevention of chronic obstructive lung disease 2017 report. GOLD executive summary," American journal of respiratory and critical care medicine, vol. 195, no. 5, pp. 557-582, 2017.

[6] L. Calzetta, M. G. Matera, and M. Cazzola, "Pharmacological interaction between LABAs and LAMAs in the airways: optimizing synergy," European Journal of Pharmacology, vol. 761, pp. 168-173, 2015.

[7] M. Cazzola and M. G. Matera, "Bronchodilators: current and future," Clinics in Chest Medicine, vol. 35, no. 1, pp. 191-201, 2014.

[8] M. G. Matera, V. Cardaci, M. Cazzola, and P. Rogliani, "Safety of inhaled corticosteroids for treating chronic obstructive pulmonary disease," Expert Opinion on Drug Safety, vol. 14, no. 4, pp. 533-541, 2015.

[9] P. Rogliani, L. Calzetta, M. Cazzola, and M. G. Matera, "Drug safety evaluation of roflumilast for the treatment of COPD: a meta-analysis," Expert Opinion on Drug Safety, vol. 15, no. 8, pp. 1133-1146, 2016.

[10] M. G. Matera, C. P. Page, L. Calzetta, P. Rogliani, and M. Cazzola, "Pharmacology and therapeutics of bronchodilators revisited," Pharmacological Reviews, vol. 72, no. 1, pp. 218-252, 2020.

[11] M. Cazzola, C. P. Page, L. Calzetta, and M. G. Matera, "Emerging anti-inflammatory strategies for COPD," The European Respiratory Journal, vol. 40, no. 3, pp. 724-741, 2012.

[12] C. Page and M. Cazzola, "Bifunctional drugs for the treatment of asthma and chronic obstructive pulmonary disease," The European Respiratory Journal, vol. 44, no. 2, pp. 475-482, 2014.

[13] Y. Shen, S. Huang, J. Kang et al., "Management of airway mucus hypersecretion in chronic airway inflammatory disease: Chinese expert consensus (English edition)," International Journal of Chronic Obstructive Pulmonary Disease, vol. Volume 13, pp. 399-407, 2018. 
[14] Z. Zhou-Suckow, J. Duerr, M. Hagner, R. Agrawal, and M. A. Mall, "Airway mucus, inflammation and remodeling: emerging links in the pathogenesis of chronic lung diseases," Cell and Tissue Research, vol. 367, no. 3, pp. 537-550, 2017.

[15] V. Dang, B. Medina, D. Das et al., "Formoterol, a long-acting $\beta 2$ adrenergic agonist, improves cognitive function and promotes dendritic complexity in a mouse model of Down syndrome," Biological Psychiatry, vol. 75, no. 3, pp. 179-188, 2014.

[16] N. J. Gross, H. S. Nelson, R. J. Lapidus et al., "Efficacy and safety of formoterol fumarate delivered by nebulization to COPD patients," Respiratory Medicine, vol. 102, no. 2, pp. 189-197, 2008.

[17] V. Kharb, V. A. Saharan, V. Kharb, H. Jadhav, and S. Purohit, "Formulation and evaluation of lipid based taste masked granules of ondansetron $\mathrm{HCl}$," European Journal of Pharmaceutical Sciences, vol. 62, pp. 180-188, 2014.

[18] L. Li, L. Xu, X. Wu, and J. Dong, "Effect of Daiqin phlegmexpelling pill on development of inflammation in rats with chronic obstructive pulmonary disease induced by lipopolysaccharide and smoke," Journal of Traditional Chinese Medicine, vol. 39, no. 1, pp. 59-64, 2019.

[19] K. E. Belmonte, "Cholinergic pathways in the lungs and anticholinergic therapy for chronic obstructive pulmonary disease," Proceedings of the American Thoracic Society, vol. 2, no. 4, pp. 297-304, 2005.

[20] M. Kondo and J. Tamaoki, "Therapeutic approaches of asthma and COPD overlap," Allergology International, vol. 67, no. 2, pp. 187-190, 2018.

[21] D. Castiglia, S. Battaglia, A. Benfante, C. Sorino, and N. Scichilone, "Pharmacological management of elderly patients with asthma-chronic obstructive pulmonary disease overlap syndrome: room for speculation?," Drugs \& Aging, vol. 33, no. 6, pp. 375-385, 2016.

[22] H. A. Kerstjens, P. Moroni-Zentgraf, D. P. Tashkin et al., "Tiotropium improves lung function, exacerbation rate, and asthma control, independent of baseline characteristics including age, degree of airway obstruction, and allergic status," Respiratory Medicine, vol. 117, pp. 198-206, 2016.

[23] M. Decramer, B. Celli, D. P. Tashkin et al., "Clinical trial design considerations in assessing long-term functional impacts of tiotropium in COPD: the UPLIFT trial," COPD, vol. 1, no. 2, pp. 303-312, 2004.

[24] T. F. Lin and S. Shune, "Chronic obstructive pulmonary disease and dysphagia: a synergistic review," Geriatrics, vol. 5, no. 3 , p. $45,2020$.

[25] M. Montes de Oca and R. Pérez-Padilla, "Global Initiative for Chronic Obstructive Lung Disease (GOLD) - 2017: la vision desde alat," Archivos de Bronconeumología, vol. 53, no. 3, pp. 87-88, 2017.

[26] H. Danahay and A. D. Jackson, "Epithelial mucushypersecretion and respiratory disease," Current Drug Targets. Inflammation and Allergy, vol. 4, no. 6, pp. 651-664, 2005.

[27] N. J. Gross, “Tiotropium bromide," Chest, vol. 126, no. 6, pp. 1946-1953, 2004.

[28] K. Komiya, S. Kawano, I. Suzaki, T. Akaba, J. I. Kadota, and B. K. Rubin, "Tiotropium inhibits mucin production stimulated by neutrophil elastase but not by IL-13," Pulmonary Pharmacology \& Therapeutics, vol. 48, pp. 161-167, 2018.

[29] B. Bosnjak, C. Tilp, C. Tomsic et al., "Tiotropium bromide inhibits relapsing allergic asthma in BALB/c mice," Pulmonary Pharmacology \& Therapeutics, vol. 27, no. 1, pp. 44-51, 2014.
[30] Y. Saito, A. Azuma, T. Morimoto et al., "Tiotropium ameliorates symptoms in patients with chronic airway mucus hypersecretion which is resistant to macrolide therapy," Internal Medicine, vol. 47, no. 7, pp. 585-591, 2008.

[31] Hospital das Clínicas da Faculdade de Medicina da Universidade de São Paulo, Heart Institute (InCor), Pulmonary Division, São Paulo/SP, Brazil and R. Athanazio, "Airway disease: similarities and differences between asthma, COPD and bronchiectasis," Clinics (São Paulo, Brazil), vol. 67, no. 11, pp. 1335-1343, 2012. 